\author{
Renato G. Jasinevicius \\ Member, ABCM \\ renatogj@sc.usp.br \\ University of Sao Paulo \\ EESC - Dept. of Mechanical Engineering \\ C. P. 359 \\ 13560-590 São Carlos, São Paulo. Brazil
}

\author{
Jaime Gilberto Duduch \\ jgduduch@sc.usp.br \\ Paulo Sérgio Pizani \\ pizani@df.ufscar.br \\ Federal University of Sao Carlos \\ Dept. of Physics \\ C.P. 676 \\ 13 565-905 São Carlos, SP. Brazil
}

\section{In-Situ Raman Spectroscopy Analysis of Re-Crystallization Annealing of Diamond Turned Silicon Crystal}

Mechanical material removal during ultraprecision machining of semiconductors crystals normally induces surface damage. In this article, Raman micro-spectroscopy has been used to probe structural alteration as well as residual stresses in the machined surface generated by single point diamond turning. The damage found is characterized by an amorphous phase in the outmost surface layer. In addition, it is reported, for the first time, the results of in-situ re-crystallization annealing of micromachined silicon monitored by micro-Raman spectroscopy. It is also shown that the annealing heat treatment influenced surface roughness: results were Rmax equal to $24.2 \mathrm{~nm}$ and $47.3 \mathrm{~nm}$ for the non treated and for the annealed surfaces, respectively.

Keywords: silicon, diamond turning, annealing, Raman spectroscopy, AFM

\section{Introduction}

The fabrication of optical elements is close related to fine surface finish since surface properties affects functional performance of high quality components/products. Several factors affecting surface integrity of components made of brittle materials may be considered such as: atomic structure modification, dislocations and subsurface microcracks. According to the literature, the achievement of ductile behaviour may directly improve the productivity of aspherical, diffractive optical components and large diameter substrates for microelectronic mechanical system (MEMS) [Yan et al. 2001, Yan 2004].

However, it is known that plastic behaviour of semiconductor crystals during single point diamond turning has its origin related to a phase transformation induced by pressure and stress [Morris et al., 1995]. The application of the concept of hydrostatic pressure in ductile machining played a fundamental role in the development of this technology to obtain large surface areas with fine surface finish and damage free [Jasinevicius, Pizani and Duduch, 2000]. Since surface structural alteration is induced in the machined surface, the mechanical and physical properties should be altered as well, affecting the component performance. This fact can be important for optical fabrication from semiconductor crystals by means of mechanical material removal such as diamond turning and grinding once this amorphous phase in the outmost surface layer has to be considered as a barrier layer with a different refractive index from that of the substrate [Jasinevicius et al., 2000]. The presence of a crystalline silicon phase remnant within the amorphous machined surface layer by means of diamond turning was probed by Raman scattering [Pizani et al. 1999]. Consequently, the possibility of unrestricted application of ductile regime diamond turning of semiconductors crystals as an ultimate finish process is constrained and thus it is usually followed by subsequent process such as chemical polishing to remove surface and subsurface damages. Moreover, micro Raman spectroscopy was also successfully applied to probe induced stresses and structural changes in silicon surfaces as a result of laser microcutting. According to the results reported [Amer et al. 2002], laser machining generated a tensile stress in the range of $0.8-1.0 \mathrm{GPa}$. In addition, laser induced amorphization ranged more than 20\% [Amer et al. 2005]. Despite of all effort addressed to the investigation of the effects of cutting process upon the machined surface, there are still some aspects to be investigated. For instance, the elimination of surface damage after machining by means of material removal mechanism or recovering the crystallinity.

In this work, an original micro Raman investigation of single point diamond turned monocrystalline silicon (100)-oriented samples machined in ductile mode is presented. The objective of the current paper is to investigate structural and physical property alterations generated by the material removal process and the possibility of recovering the original crystal phase of the machined surface. In-situ Raman spectroscopy analysis was carried out during annealing of the machined surface in order to characterize the recovering of the crystalline phase.

\section{Experimental Method}

Ductile regime diamond turning tests were carried out on a commercially available diamond turning machine. Facing cuts were performed on monocrystalline silicon $(\mathrm{c}-\mathrm{Si})$ polished samples $(10 \mathrm{x}$ $10 \mathrm{~mm}^{2}$ ) and $500 \mu \mathrm{m}$ thick with (100) surface orientation. The cutting conditions and tool geometry are better presented in Table 1. The cross feed direction was outside to inside. These conditions provided ductile response for the two first conditions with mirrorlike surface finish and the last brittle response during machining. Figure 1 gives the schematic diagram illustrating the machining geometry with round nose tool.

Table 1. Tool geometry and cutting conditions used in the cutting tests.

\begin{tabular}{lc}
\hline Tool geometry & Dimensions \\
\hline Tool nose radius $(\mathrm{mm})$ & 0.65 \\
Rake angle $\left({ }^{\circ}\right)$ & -25 \\
Clearance angle $\left({ }^{\circ}\right)$ & 12 \\
Spindle speed $(\mathrm{rpm})$ & 1000 \\
Feed rate $(\mu \mathrm{m} / \mathrm{min})$ & $1.25,2.5$ and 8.0 \\
Depth of cut $(\mu \mathrm{m})$ & 5 \\
\hline
\end{tabular}

Paper accepted October, 2006. Technical Editor: Anselmo Eduardo Diniz. 


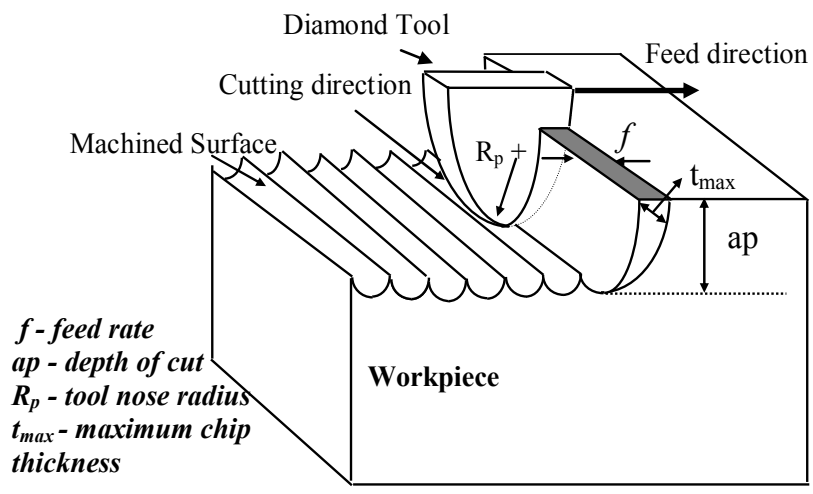

Figure 1. Schematic diagram illustrating machining geometry with round nose tool.

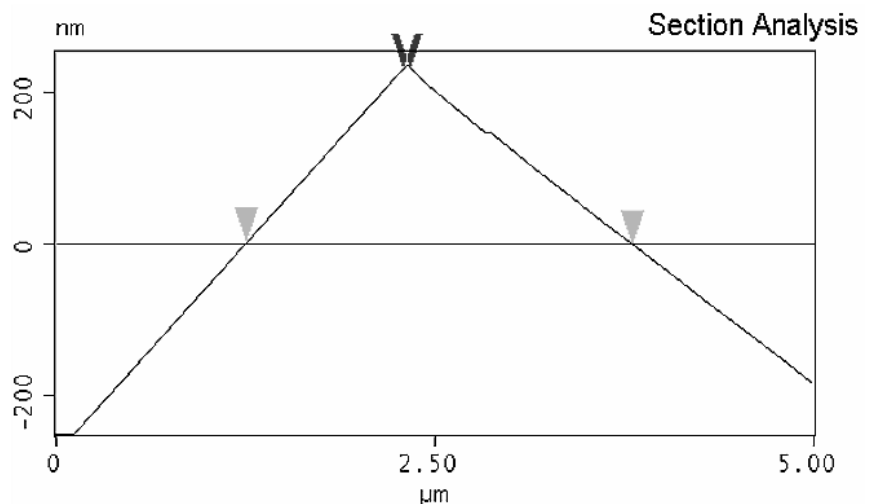

(a)

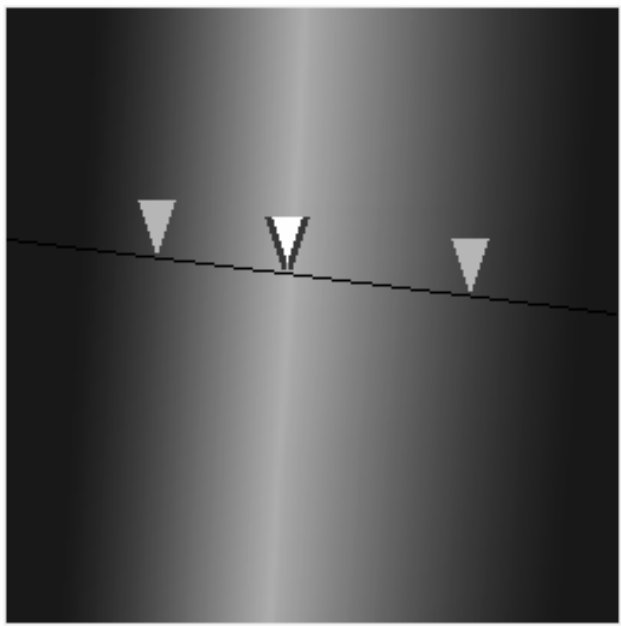

(b)

Figure 2. Analysis made by atomic force microscope of the diamond tool cutting edge. a) three dimensional image of part of the cutting edge; b) section analysis of the diamond tool cutting edge used in the machining tests. The radius of the cutting edge is estimated to be smaller than 100 $\mathrm{nm}$.

A scanning electron microscope Zeiss, model DSM 960, operated with an electron beam of $20 \mathrm{kV}$ was used for the observations of the chips. Only fresh diamond tool were used to perform the cutting tests. The single point tool used in this work was round nose single crystal diamond tools (Contour Fine Tooling). Figure 2 presents a section analysis made by AFM of the tool cutting edge showing that the radius of the cutting edge is smaller than $100 \mathrm{~nm}$. Table 1 describes tool geometry used in the cutting test. Synthetic water-soluble oil was used as the lubricant and coolant during turning. Atomic force microscopy (AFM) was used in order to probe the surface machined in the ductile regime. It was operated with a standard $50-60^{\circ}$ conical silicon nitride stylus of 15 $20 \mathrm{~nm}$ radius tip, with cantilever spring constant of $\sim 0.06 \mathrm{~N} / \mathrm{m}$. Conventional contact mode was employed where the stylus is scanned raster style over, with contact forces of typically 10-100 $\mathrm{nN}$.

The Raman measurements were performed using a T64000 Jobin-Yvon micro spectrometer to probe of disorder effects, using the $514.5 \mathrm{~nm}$ line of an argon ion laser. For this line, the penetration depth of the light is about $340 \mathrm{~nm}$ for c-Si. However, for amorphous silicon (a-Si), the optical absorption coefficient can reach one order of magnitude higher when compared to $\mathrm{c}-\mathrm{Si}$, leading to penetration depths of about tenths of nanometers, depending on the degree of amorphization [Pizani et al. 1999]. This fact may lead to different Raman spectra when different cutting conditions are employed or different samples, mainly with different doping levels, are analyzed. The laser power was kept low at about $0.5 \mathrm{~mW}$ in order to avoid heating effects, an important care to be considered for analyzing highly disordered samples. The machined sample was annealed in micro furnace LINKAN TS-1500 attached to a micro Raman spectrometer.

\section{Results and Discussion}

Three-dimensional AFM images of the diamond turned surfaces in the ductile mode under three different cutting conditions are shown in Figure 3. In Fig. 3 (a), the cross-feed of the cutting tool is $1.25 \mu \mathrm{m} \mathrm{rev}^{-1}$. The cut grooves can be clearly seen, regularly spaced and running parallel with cutting direction which confirms the absence of chatter vibration. The surface roughness Rmax measured was equal to $15.89 \mathrm{~nm}$. In this case single point diamond turning has achieved fully ductile material removal. A closer examination of the machined surface with $2.5 \mu \mathrm{m} \mathrm{rev}^{-1}$, in Fig. 3 (b), shows also a crack free surface. The surface roughness Rmax measured was equal to $24.25 \mathrm{~nm}$. This can be considered an expected trend since the feedrate was increased. Fig. 3 (c) shows the three-dimensional image of the surface generated in the brittle mode. The surface is severely damaged with microcracks along with parallel lines which corresponds to the tool feed marks.

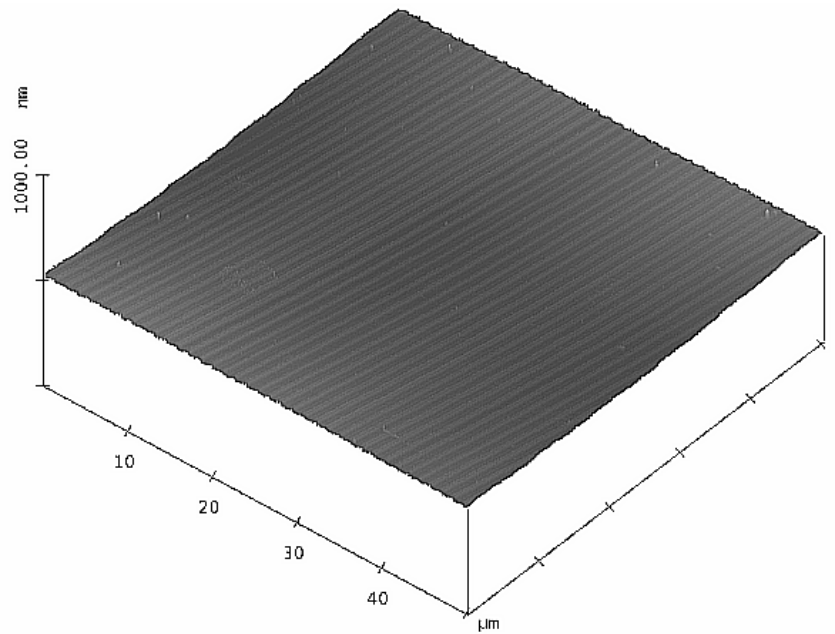

(a)

Figure 3. Typical three-dimensional surface finish of the single-point diamond turned specimen obtained by atomic force microscope; a) the cutting conditions feed rate: $f=1.25 \mu \mathrm{m} \mathrm{rev}{ }^{-1}$ and depth of cut $a_{p}=5 \mu \mathrm{m}$; b) feed rate $f=2.5 \mu \mathrm{m} \mathrm{rev}{ }^{-1}$ and depth of cut $a_{p}=5 \mu \mathrm{m}$ and; the cutting conditions feed rate $f=8.0 \mu \mathrm{m} \mathrm{rev}{ }^{-1}$ and depth of cut $a_{p}=5 \mu \mathrm{m}$. 


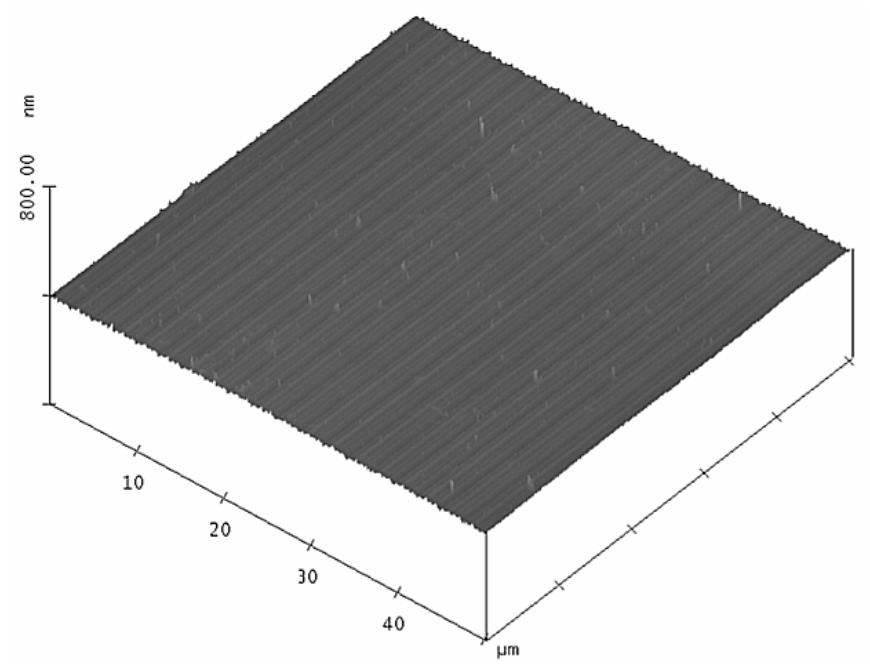

(b)

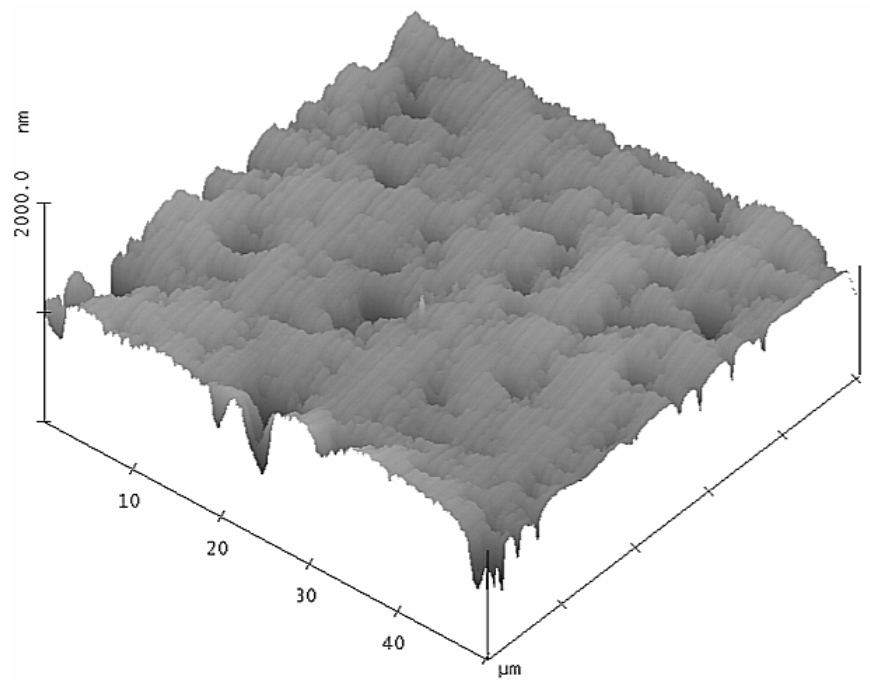

(c)

Figure 3. (Continued).

Raman spectra $a$ and $b$ of Figure 4 are of the machined samples in the ductile mode with feedrates of 1.25 and $2.5 \mu \mathrm{m} / \mathrm{rev}$, respectively. Both Raman spectra show the peaks of crystalline phase of silicon (c-Si) broadened and shifted from 521 to $523 \mathrm{~cm}^{-1}$. These characteristics are indicative of structural disorder and the presence of compressive residual stress. Moreover, the broad band at about $470 \mathrm{~cm}^{-1}$, attributed to the optical band of silicon, corroborates with the presence of amorphous $\mathrm{Si}$ (a-Si), probably produced by the releasing of the high pressure applied by the tool tip during machining: as it is well known, the pressure induced transition from diamond structure to $\beta$-tin is irreversible, leading to the amorphization of $\mathrm{Si}$. This is a thin amorphous layer with thickness smaller than the penetration depth of the light, generally some tenths to hundredths nanometers [Shibata et al., 1994; Jasinevicius et al., 2005; Inamura et al. 1997], on the machined surface. The value of this stress can be estimated by the formula proposed by Weinstein \& Piermarini (1975). The value of the residual stress was estimated as $0.3 \mathrm{GPa}$ for both feed rates, 1.25 and $2.5 \mu \mathrm{m} / \mathrm{rev}$, respectively.

For $8.0 \mu \mathrm{m} / \mathrm{rev}$, which leads to a brittle condition spectrum c (Fig. 4), the Raman peak is very similar to the c-Si, but the full width at half maximum is twice that of the polished surface spectrum d (Fig. 4). This indicates structural disorder of the c-Si.
Furthermore, there are no features at $470 \mathrm{~cm}^{-1}$, indicating that no phase transition from diamond-type structure to $\beta$-tin occurred. It is worth to mentioning that neither spectra shown in Figure 4 shows any sign of metastable phases such as those found in the literature detected in dicing and scratching tests of monocrystalline silicon [Gogotsi et al., 1999, 2001].

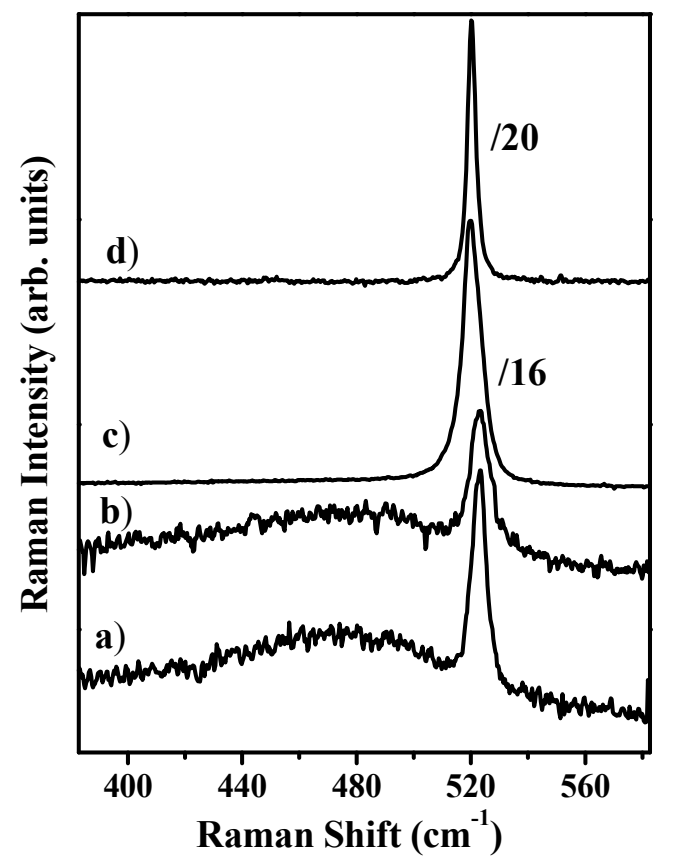

Figure 4. a) Raman spectra (performed with the $514 \mathrm{~nm}$ exciting light) of the silicon sample machined in the ductile mode: a) feedrate $=1.25$ $\mu \mathrm{m} / \mathrm{rev}$; b) feedrate $=2.5 \mu \mathrm{m} / \mathrm{rev}$. (Both spectra are dislocated upward indicating that the surface is under compressive residual stress); c) feedrate $=8.0 \mu \mathrm{m} / \mathrm{rev}$; and d) Pristine Silicon.

Figure 5 shows the analysis of the chips found on the machined surface with cutting condition of $1.25 \mu \mathrm{m} / \mathrm{rev}$. Figure 5a) presents a SEM photomicrograph of silicon chips removed. The ribbon-like chips indicate a ductile mode for the material removal. Figure $5 \mathrm{~b}$ ) presents a spectrum of the chips found on the machined surface probed by micro Raman spectroscopy. The spectrum shows a higher intense peak around $500 \mathrm{~cm}^{-1}$, and other peaks appear around 516 $\mathrm{cm}^{-1}$ and $521 \mathrm{~cm}^{-1}$, which are characteristic of single crystal cubic diamond phase of silicon. The two former peaks, between 500-515 $\mathrm{cm}^{-1}$, has been assigned to Si-IV, a hexagonal diamond or Si-I nanocrystalline cubic diamond [Kailer, Nickel and Gogotsi, 1997]. Five different phases of silicon were probed by Jasinevicius et al. [2005] in silicon chips found on the diamond tool rake face which reported besides a-Si and c-Si, Si-III (a body-centered cubic structure), Si-IV (hexagonal diamond structure) and Si-XII (a rhombohedral distortion of the Si-III). 


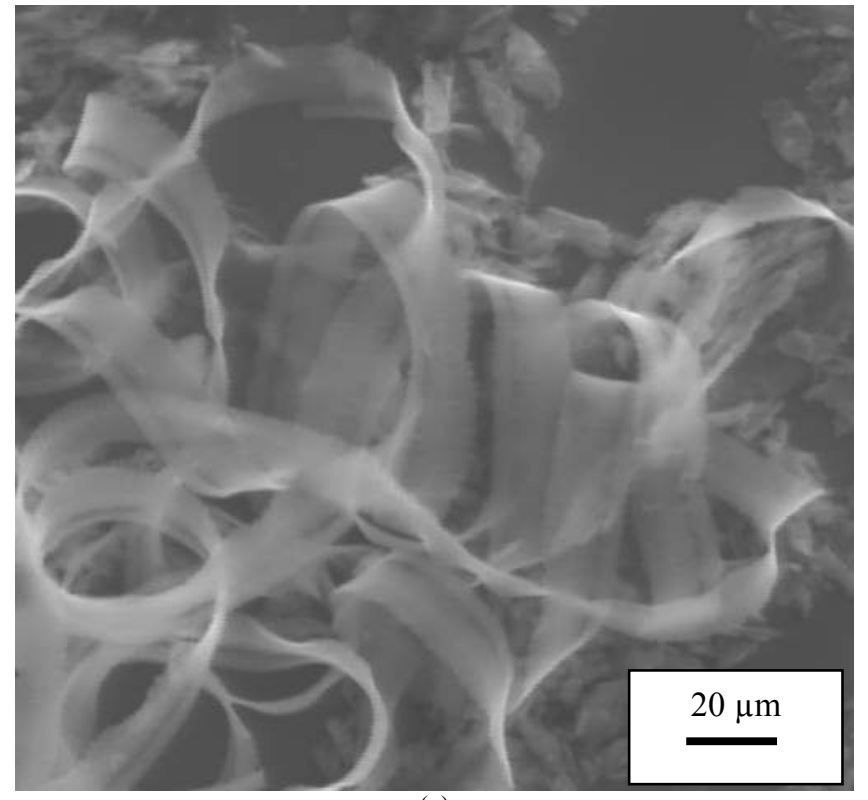

(a)

Figure 5. a); Scanning electron micrograph of a chip left on the surface of the machined silicon sample in the ductile regime; b) micro Raman Spectrum of the ductile chips found on the machined surface.

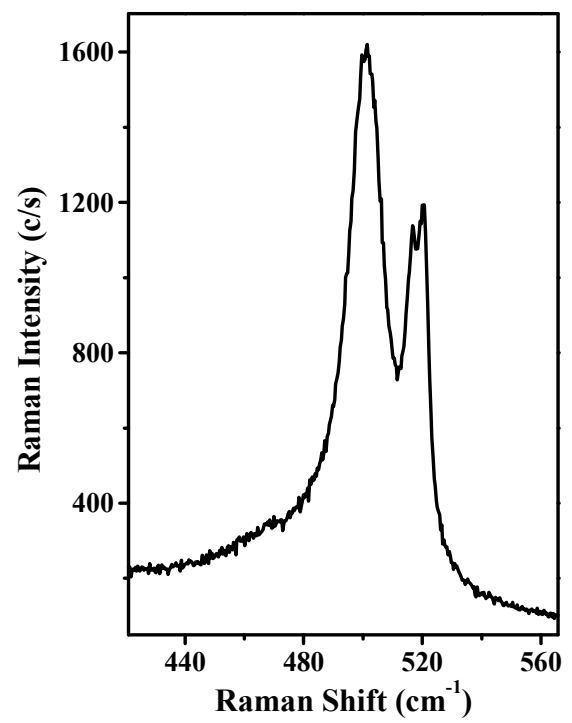

(b)

Figure 5. a); Scanning electron micrograph of a chip left on the surface of the machined silicon sample in the ductile regime; b) micro Raman Spectrum of the ductile chips found on the machined surface.

Figure 6 shows Raman spectra obtained during annealing from the machined sample with in situ analysis in a micro furnace. Spectra a) to d) (Figure 6) are made after machining under annealing temperature of $200{ }^{\circ} \mathrm{C}, 400{ }^{\circ} \mathrm{C}$ and $600{ }^{\circ} \mathrm{C}$, respectively. It is worth mentioning that in spectrum a) both amorphous and crystalline phase are present. From a) to c) the spectra depicts an expected broadening and negative frequency shift of the Raman peak due to the softening caused by the increase of the temperature. However, when the temperature reaches $600{ }^{\circ} \mathrm{C}$ there is a spectacular increase in the Raman peak intensity along with the drastic decreasing of the amorphous band at about $470 \mathrm{~cm}^{-1}$ (spectrum d), indicating the crystalline recovery. After annealing, cooling down to the room temperature, the crystalline phase is completely recovered, the Raman peak recovering the full width at half maximum to at about 3 $\mathrm{cm}^{-1}$ and is characterized by the repositioning of the silicon peak at $521.6 \mathrm{~cm}^{-1}$, characteristics of the cubic diamond structure of silicon at room temperature, as shown in Fig. 7.

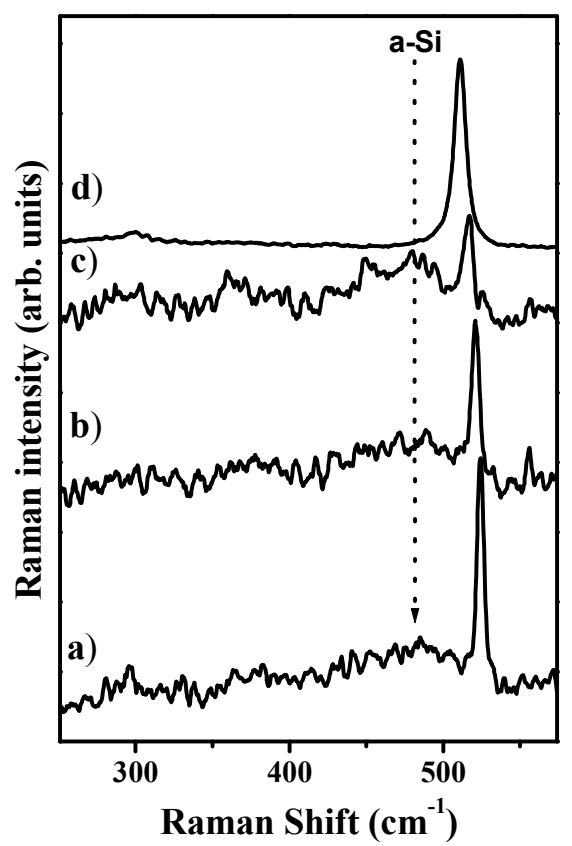

Figure 6. Raman spectra of the silicon (100) a) monocrystalline silicon after machining at room temperature of $20^{\circ} \mathrm{C}$; b) machined surface during annealing $\left(200^{\circ} \mathrm{C}\right)$; and c) machined surface during annealing $\left(400{ }^{\circ} \mathrm{C}\right)$; and d) machined surface during annealing $\left(600^{\circ} \mathrm{C}\right)$.

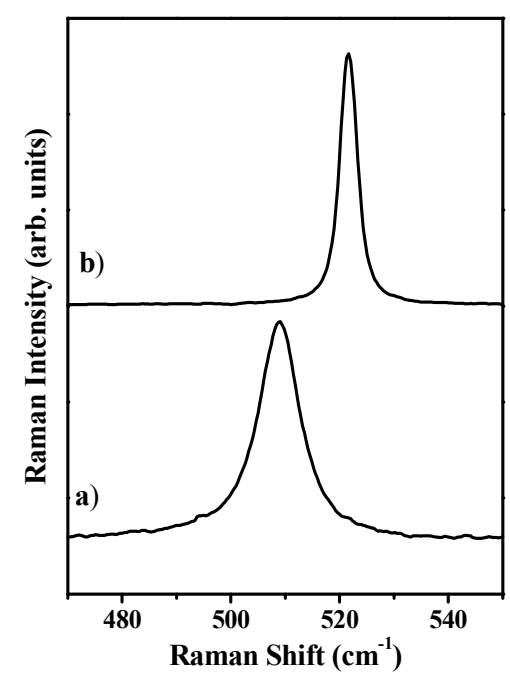

Figure 7. Raman spectra of the silicon (100) a) machined surface at at annealing temperature of $600{ }^{\circ} \mathrm{C}$; b) machined surface after annealing at room temperature $20^{\circ} \mathrm{C}$.

Figure 8 shows a comparative section analysis of the surface machined and annealed by heat treatment. The surface finish is different in the heat-treated surface, i.e., the peak-to-valley surface roughness increased with the heat treatment. This can be better 
evaluated by means of the Rmax parameter, which estimates the peak-to-valley height. The value of Rmax was increased from 24.25 $\mathrm{nm}$ (after machining) to $47.32 \mathrm{~nm}$ in the heat-treated sample. The same trend was noticed in the $\mathrm{Ra}$ value. The value of $\mathrm{Ra}$ was increase from $1.6 \mathrm{~nm}$ to $2.4 \mathrm{~nm}$ after annealing. This increase in the roughness parameter with annealing treatment has no explanation in the literature.

The heat treatment proceeded showed that the surface crystallinity was recovered but the microtopography of the machined surface undergone an expansion. This might be an expected result since that contrary was the most unlikely to occur. It is known that when the intermediate $\beta$-Sn ( $\mathrm{Si}-\mathrm{II})$ structure forms from the diamond structure (Si-I) there is volume decrease of $22 \%$ (denser phase) and when the pressure is released the amorphous phase is still with $8 \%$ decrease in volume. Consequently, it would be expected that after the annealing there would be an incomplete volume recovery and an increase on the surface roughness.

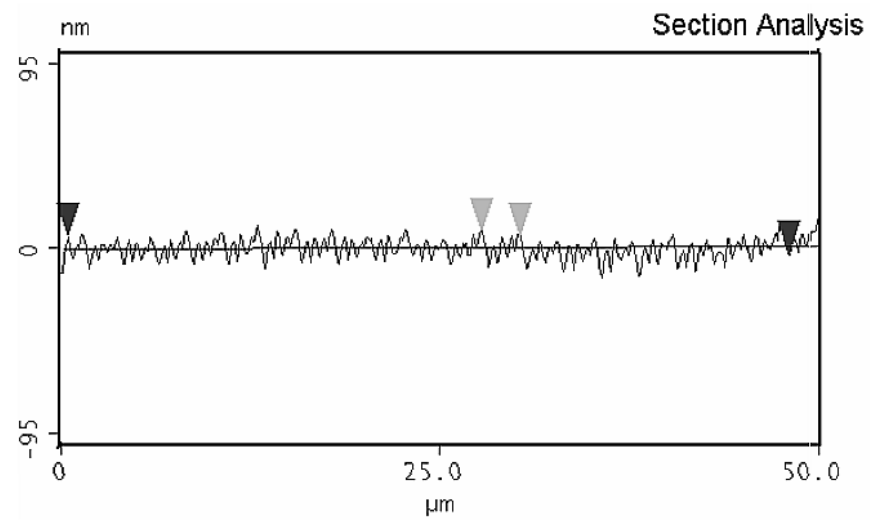

(a)

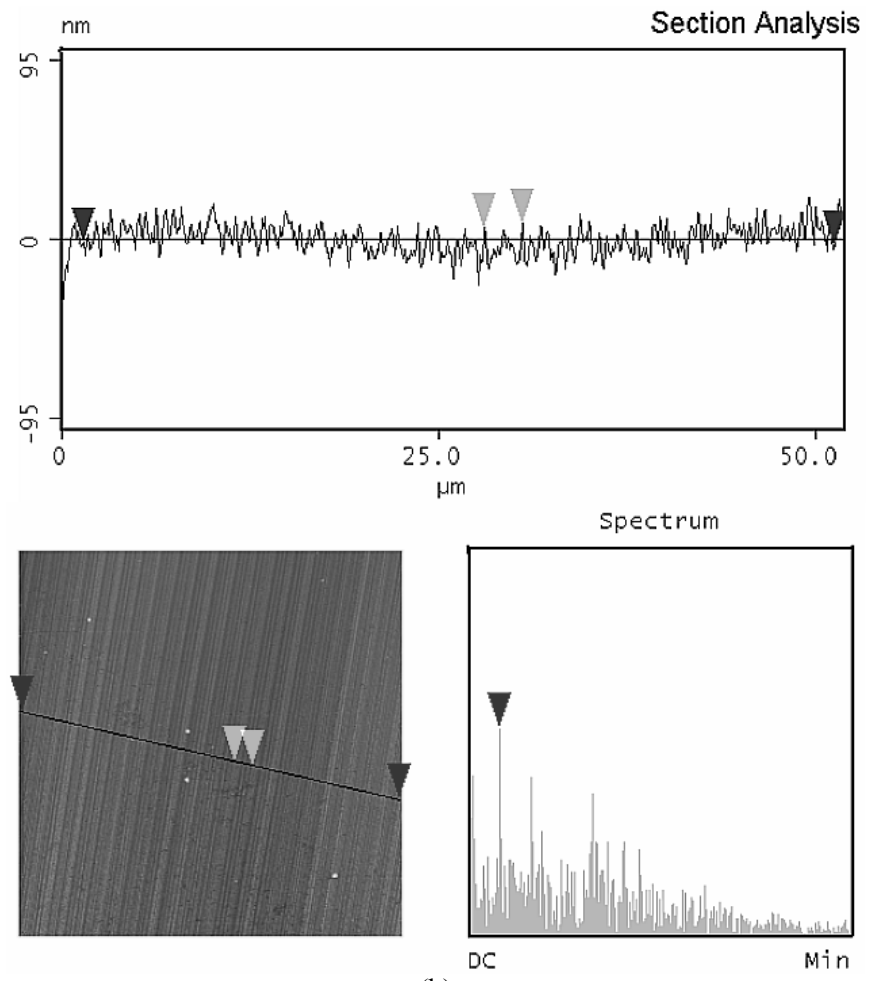

(b)

Figure 8. Images made by AFM of section analysis of the ductile diamond turned silicon surfaces, (a) machined surface without heat treatment and, (b) machined surface after annealing.

\section{Conclusions}

This paper has shown that silicon can be machined in the ductile mode at room temperature when appropriate cutting conditions are used. Ribbon-like chips are formed during cutting in the same way as is observed when ductile metals are cut. The mechanism responsible for chip formation process, in the ductile mode, might be the same for metals. This anomalous plasticity is recognized to be resultant from the intermediate pressure/stress metallic phase transformed material. Raman spectra of the chip showed different phase from that observed in the machined surface. On the contrary when the cutting conditions are above the critical conditions, the brittle failure is the predominant mode.

The Raman scattering results demonstrated that ductile diamond turned silicon surfaces lead to amorphization, showing that the outmost layer of the sample machined in the ductile mode was found to be a mixture of crystalline and amorphous phases. It is important that the machining parameters may be constrained within a certain range: the machining condition must lead to the transformation from the semiconductor to metallic phase and consequently to the ductile mode of machining.

The heat treatment carried out up to $600{ }^{\circ} \mathrm{C}$ showed that it is possible to recover a good crystalline quality of the transformed surface layer. This is a very important result since the structural state of the surface is determinant for the electronic transport characteristics in devices, although this may increase surface roughness. In addition, it was shown for the first time the behaviour of the re-crystallization of the surface during annealing of silicon crystal.

Finally, the use of different characterization techniques, Raman spectroscopy along with scanning electron microscopy and atomic force microscopy, demonstrated to be powerful tools to investigate surface integrity of diamond turned semiconductors single crystals.

\section{Acknowledgements}

The authors would like to acknowledge the financial support of FAPESP, CNPq and CAPES (Brazil).

\section{References}

Amer, M. S., Dosser, L., Le Clair, S., Maguire, J.F., 2002, Induced stresses and structural changes in silicon wafers as a result of laser micromachining. Appl. Surf. Science, Vol.187, pp.291-296.

Amer, M.S., El-Ashry, M.A., Dosseb, L.R., Hix, K.E., Maguire, J.F, Irwin, B., 2005, Femtosecond versus nanosecond laser machining: comparison of induced stresses and structural changes in silicon wafers. Appl. Surf. Science, Vol. 242, No.1-2, pp.162-167.

Kailer, A., Nickel, K. G., Gogotsi, Y. G., 1997, Phase transformations in materials studied by micro-Raman spectroscopy of indentations Mat. Res. Innovat., Vol. 1, pp. 3-9.

Gogotsi, Y.G., Baek, C., Kirscht, F., 1999, Raman microspectroscopy study of processing-induced phase transformations and residual stress in silicon. Semicond. Sci. and Technol., Vol. 14, pp. 936-944.

Gogotsi, Y, G., Zhou, G., Ku, S. S., Cetinkunt, S., 2001,Raman microspectroscopy analysis of pressure-induced metallization in scratching of silicon. Semicond. Sci. and Technol., Vol. 16, pp. 345-352.

Inamura, T., Shimada, S., Takezawa, N., Nakahara, N., 1997, Brittle/ductile transition phenomena observed in computer simulation of machining defect free monocrystalline silicon. Annals of the CIRP, Vol. 46, No.1, pp. 31-34.

Jasinevicius, R. G., Pizani, P. S., Duduch, J. G., 2000, Brittle to ductile transition dependence upon the transition pressure value of semiconductors in micromachining. J. Mat. Res., Vol. .15, pp. 1688-1692.

Jasinevicius, R. G., Santos, F.J., Pizani, P.S., Duduch, J. G., Porto , A. J. V., 2000, Surface amorphization in diamond turning of silicon crystal investigated by transmission electron microscopy. J. of Non-Crystal. Sol., Vol. 272, pp. 174-178. 
Jasinevicius, R.G., Porto, A.J.V., Duduch, J.G., Pizani, P.S., Lanciotti Jr., F., Santos, F.J., 2005, Multiple phase silicon in submicrometre chips removed by diamond turning. Journal of the Brazilian Society of Mechanical Engineering, Vol. 27, No. 4, pp. 440-448.

Kailer, A. Nickel, K.G. Gogotsi, Y.G., 1999, Phase transformations of silicon caused by contact loading. J. of Raman Spectroscopy, Vol. 30, pp. 939-947.

Morris, J.C., Callaham, D.L., Kulik, J., Patten, J.A., Scattergood, R.O., 1995, Origins of the ductile regime in single point diamond turning of semiconductors. J. Am. Ceram. Soc., Vol. 78, pp. 2015-2020.

Pizani, P. S., Jasinevicius, R.G., Duduch, J.G., and Porto, A J.V., 1999, Ductile and Brittle damage in single point diamond turned silicon probed by Raman scattering . J. of Mat. Sci. Lett., Vol. 18, pp. 1185-1187.
Shibata T., A., Ono, K., Kurihara, E., Makino, M., Ikeda, 1994, Crosssection transmission electron microscope observations of diamond turned single crystal Si surfaces. Appl. Phys. Lett., Vol. 65, pp. 2553-2555.

Weinstein, B.A. Piermarini, G.J., 1975, Raman Scattering and phonon dispersion in $\mathrm{Si}$ and $\mathrm{GaP}$ at very high pressure. Phys. Rev. B, Vol. 12, No.4, pp. 1171-1186.

Yan, J. Yoshino, M. Kuriagawa, T., Shirakashi, T., Syoji, K., Komanduri, R., 2001, On the ductile machining of silicon for micro electro-mechanical systems (MEMS), opto-electronic and optical application. Mat. Sci. and Engg. A, Vol. 297, pp. 230-234.

Yan, J., 2004, Laser micro-Raman spectroscopy of single-point diamond machined silicon substrates. J. Appl. Phys., Vol. 95, pp. 2094-2101. 